\title{
Observational Studies in Bariatric Surgery
}

\author{
Fatemeh Sadat Hosseini-Baharanchi ${ }^{1{ }^{1}}$ \\ ${ }^{1}$ Minimally Invasive Surgery Research Center, Iran University of Medical Sciences, Tehran, Iran \\ "Corresponding author: Fatemeh Sadat Hosseini-Baharanchi, Assistant Professor, Minimally Invasive Surgery Research Center, Iran University of Medical Sciences, Sattarkhan \\ Ave, Tehran, Iran. Tel/Fax: +98-2186704623, E-mail: hosseini.mstat@gmail.com
}

Received 2018 January 03; Revised 2018 February 02; Accepted 2018 February 25.

\begin{abstract}
In medical literature, studies are divided into two categories; experimental and observational settings. Experimental studies, entitled randomized controlled trials could test the relationship between exposure and outcome experimentally via control group and random allocation. Observational settings include either analytical or descriptive studies. Descriptive studies consist of case reports and case series that are helpful in present the experience of a case or a series of cases with similar diagnoses in detail which results in hypothesis generation. Cross-sectional studies, as analytical designs, are not capable to survey the temporality of exposure and outcome as simultaneously exposure and outcome status are measured. In case-control studies, subjects follow back from outcome to exposure. The rare diseases are recommended to study using case-control setting to save expenses and time. Both exposure measurement and patient selection is before disease detection in cohort studies. Therefore, they are inefficient for rare diseases or diseases with long latency. Cohort studies are time consuming with high cost and loss to follow-up. This paper elaborately reviews the features, advantages, and disadvantages of different types of observational and experimental studies.
\end{abstract}

Keywords: Observational Studies, Case-Control Studies, Cohort Studies, Bariatric Surgery, Experimental Studies, Review

\section{Introduction}

There are two categories of studies in medical field such as experimental and observational settings. In the experimental setting known as randomized clinical trial (RCT), the researcher assigns the patients to a given procedure or a new treatment to compare the outcomes between groups (1). The outcomes are likely compared with a placebo or a standard treatment. The patients should receive different treatments randomly to make the study groups homogenous. Small or relatively small sample size is one of the most prominent limitations of clinical trials. As an example, recently a randomized controlled trial found that metabolic-bariatric surgery was more effective than medical treatment in diabetes remission in morbidly obese patients with type 2 diabetes (2).

In contrast, in some cases clinicians are not able to allocate exposure or treatment to the patients. As a result, they are merely being able to observe and measure the outcomes called observational setting. The majority of the studies in surgical researches are of this typical setting. In observational setting, absence or presence of a comparison group can lead to descriptive and analytical studies, respectively. Often descriptive studies including case reports and case series do not have any prior hypotheses whereas analytical studies including cross-sectional, case-control, and cohort studies answer questions throughout the hypotheses testing via comparison between groups. For a better understanding, Figure 1 depicts the categorization of study designs in terms of descriptive and analytical settings. The aim of this paper is to focus on the characteristics, advantages, and disadvantages of the observational studies, and elaborated presentation of RCTs is remained for further issues.

\section{Case Report and Case Series}

A report on a patient and on a series of patients, with one or more outcomes, is titled case report and case series, respectively. These studies present some of the important aspects of succession and coherence over time, and are mainly helpful in hypotheses generation. As a case in point, a study described a morbidly obese patient who presented severe protein malnutrition after Roux-en-Y gastric bypass surgery (3).

In these types of studies, the sampling process is either based on exposure and outcome, or includes patients with specific outcomes (mortality and morbidity are mainly outcomes of interests) regardless of the exposure. Thus, risk ratios, absolute risks, and other effect size indexes 


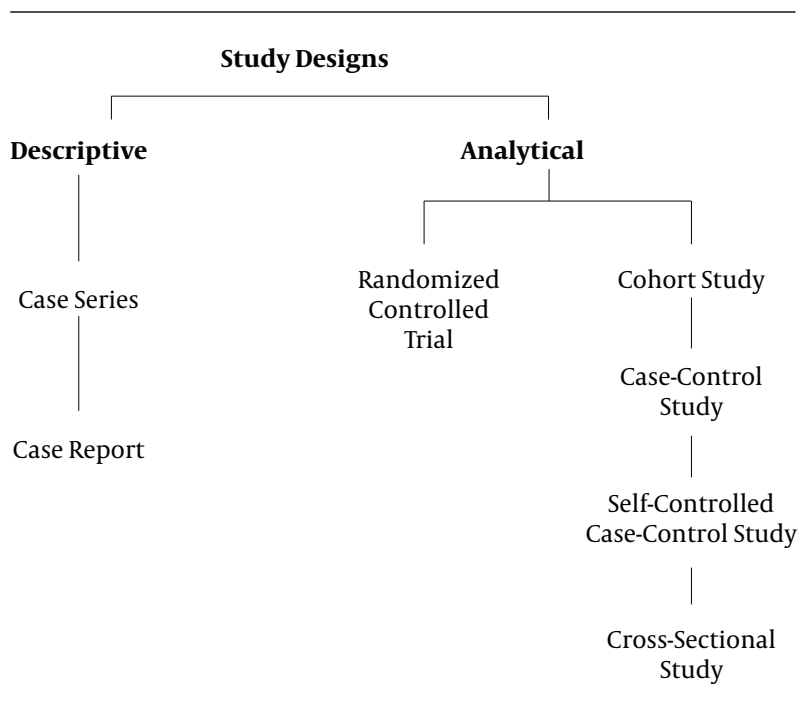

Figure 1. Study designs in terms of descriptive and analytical settings

could not be calculated. There is no need to follow a consecutive sampling in case series studies (4). It is sensible to generalize that case series has outcome-based sampling. It is noteworthy that patients with a certain manifestation included the case series, thus a control group is not involved.

\subsection{Cross-Sectional Studies}

Exposure and outcome are measured at the same point in time in cross-sectional studies. This type of study, as a snapshot of the population, enables the researcher to measure the prevalence (frequency of a certain condition) of an outcome, an exposure as well as other variables of interest (5).

One of the demerits of these studies is that it may be complicated to define the cause and effect relationship, since no dimension of time exists. This approach is not widely-used in surgical research area. Screening studies are typical examples of cross-sectional studies, for instance, detection of a definite condition such as morbidly obese in a certain subset of population e.g. adults or adolescence in a very short period of time. As another example, in a cross-sectional pilot study, the effect of dumping on weight loss in patients who underwent conversion of failed restrictive surgery into Roux-en-Y gastric bypass surgery was estimated (6).

\subsection{Case-Control Studies}

In case-control studies, the subjects are defined by outcome not by exposure (7) i.e. the sampling is outcomebased (4). It is noteworthy to mention that the time direction of these studies is retrospective.
All types of case-control studies have a control group including subjects who had a manifestation other than the prespecified outcome; healthy or survived individuals. In self-controlled case-control (case-crossover) studies, each individual is on control by their data (8). The interpretation of risk ratios and absolute risks are meaningful in these studies. Case-control studies naturally tend to bias, i.e. researchers have to deal with different kind of biases such as recall bias. Different definitions as well as different successful techniques over time should be considered in these studies especially in long retrospective series.

As an illustration, to evaluate the possible association between laparoscopic sleeve gastrectomy (LSG) and orthotopic liver transplant (OLT), OLT-LSG patients were matched according to age, sex, body mass index, and year to non-OLT-LSG patients. The outcome is defined as longterm weight loss with comorbidity resolution (9).

\subsection{Cohort Studies}

In cohort studies comparing case-control studies, subjects are defined by the exposure and followed up to outcome, so the direction is prospectively in time. For instance, if the subjects in the exposed group have a higher or lower frequency of a certain outcome than the unexposed subjects, the association between exposure and outcome will be evident. It is necessary to distinguish between cohort direction and obtaining data; cohort direction is prospective whereas data gathering could be related to either the past or now to the future. Another variation of cohort is ambidirectional (7): imagine a researcher is going to compare the effect of sleeve gastrectomy with gastric bypass on weight loss of morbidly obese patients. In addition, he hypothesized that the type of surgery is associated considerably with the cancer of the digestive system in later life. Figure 2 shows the schematic diagram of different types of cohort studies (7).

Selection bias should be considered as inevitable issue in cohort studies; in the abovementioned example, a reasonable weight loss and lower rate of complication in a group of the patients may not be due to the surgery type, while perhaps it is due to the characteristics of the selected patients (10). Admittedly, the researchers are likely mislead in a cohort analysis with testing the association between the outcome and too many possible factors, hence it is highly recommended to determine main questions of interest before conducting the study (4).

Framingham study is one of the most prominent cohorts in which the residents of the city of Framingham in Massachusetts, USA are followed in order to define the factors associated with the coronary heart disease (11). A prospective cohort study was conducted to include 


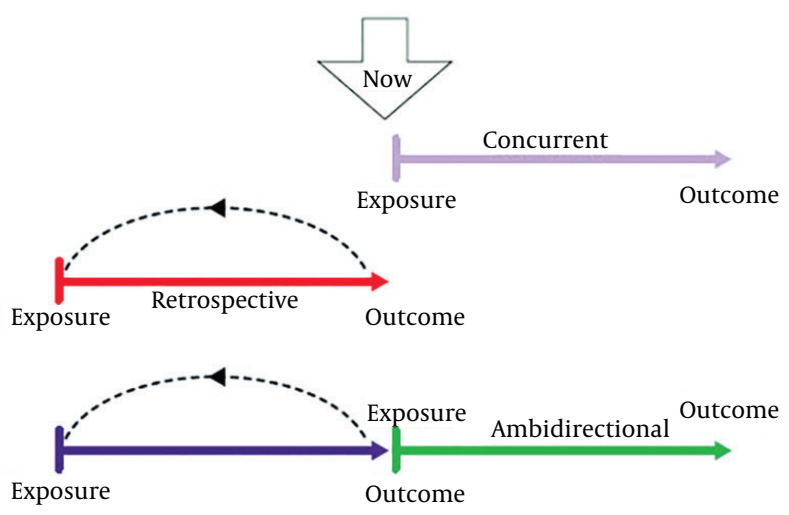

Time

Figure 2. Schematic diagram of different cohort studies (Grimes DA and Schulz KF)

women who underwent bariatric surgery and were followed to assess their menstrual cycle, sexual behavior, and contraception use during 12 months post-operatively (12). For further illustration of cohort bariatric surgery, we can address the Scandinavian obesity surgery registry (SOReg) (13), the Swedish obese subjects (SOS) study (14), and national obesity surgery in Iran (15).

It is noteworthy that the ability of definition of inclusion criteria and control group, as well as random allocation (individuals to either treatment or control group), and blinding (neither investigator nor patient is aware of the treatment) increases analytical power of the experimental design (1). Obviously, cohort and then case-control studies have a lower level of evidence due to lower analytical power because of not being able to manage the treatment distribution and other mentioned characteristics (10).

\section{Discussion}

This paper elaborately reviewed the characteristics of different types of observational study designs. However, each design has its own advantages and disadvantages which is presented in Table 1 . Furthermore, this Table shows the trend of increasing knowledge about the relationship between disease and exposure. Typically, case report and case series can be used for very rare disease with few established risk factors, whereas they could not study neither disease prevalence nor causal relationships (4).

Cross-sectional studies, the weakest type of observational studies, is appropriate for frequent expression with long duration such as chronic diseases and nonfatal conditions. Thus, in the case of quickly emerging and rare diseases they will not be helpful. Moreover, cross-sectional studies cannot determine either the incidence of disease or temporality of exposure and effect (5).

The investigation of association between exposure and outcome in the case of rare diseases through a less expensive and time consuming design, case-control studies could be a priority. Selection bias and exposure measurement after disease occurrence are of the disadvantages of this type of study (4).

The advantage of cohort study is either to measure the exposure or to select patient before the disease detection, which results in meaningful interpretation of the association between exposure and outcome. It is worthy to note that cohort studies in contrast with case-control studies would be expensive and time-consuming, and also inefficient for rare diseases or diseases with long latency. Loss to follow-up which leads to missing data is the most notable disadvantages (7).

Researchers are capable of testing the prespecified relationships in RCTs; including control group for comparison as well as random assignment. Different ethical issues surrounding RCTs should be kept in mind at the time of determination of the main aim of the study. Moreover, it is necessary to emphasize that the high quality and accuracy of RCTs are accompanied by a more expensive and timeconsuming process (1).

\subsection{Conclusion}

In summary, RCTs guarantee more evident results, taking into account biases and financial resources limitations 


\begin{tabular}{|c|c|c|c|c|}
\hline & Type of Study & Aim of Study & Advantages & Disadvantages \\
\hline \multirow{5}{*}{$\begin{array}{l}\text { Increasing knowledge of } \\
\text { disease/exposure (Up to } \\
\text { Down) }\end{array}$} & Case report/case series & Generates hypotheses & $\begin{array}{l}\text { 1- Informative for very rare } \\
\text { disease with few established } \\
\text { risk factors; } 2 \text { - Characterizes } \\
\text { averages for disorder. }\end{array}$ & $\begin{array}{l}\text { 1- Cannot study cause and } \\
\text { effect relationships; } 2 \text { - Cannot } \\
\text { assess disease frequency. }\end{array}$ \\
\hline & Cross-sectional study & Measures prevalence & $\begin{array}{l}\text { 1-Suitable for frequent with } \\
\text { long duration of expression } \\
\text { such as chronic diseases and } \\
\text { nonfatal conditions. }\end{array}$ & $\begin{array}{l}\text { 1-Weakest type of } \\
\text { observational studies; } 2 \text { - } \\
\text { Cannot determine incidence } \\
\text { of disease; } 3 \text { - Cannot detect } \\
\text { temporality of exposure and } \\
\text { effect; } 4 \text { - Inappropriate for } \\
\text { quickly emerging and rare } \\
\text { diseases. }\end{array}$ \\
\hline & Case-control study & $\begin{array}{l}\text { Investigates the relationship } \\
\text { between exposure and } \\
\text { outcomes }\end{array}$ & $\begin{array}{l}\text { 1- Less expensive and } \\
\text { time-consuming; 2-Efficient } \\
\text { for studying rare diseases. }\end{array}$ & $\begin{array}{l}\text { 1- Inappropriate when disease } \\
\text { outcome for a specific } \\
\text { exposure is not known at } \\
\text { start of study; 2- Exposure } \\
\text { measurements taken after } \\
\text { disease occurrence; 3- Disease } \\
\text { status can influence selection } \\
\text { of subjects. }\end{array}$ \\
\hline & Cohort study & $\begin{array}{l}\text { Defines the meaning of the } \\
\text { relationship between } \\
\text { exposure and outcome }\end{array}$ & $\begin{array}{l}\text { 1- Exposure status determined } \\
\text { before disease detection; } 2 \text { - } \\
\text { Subjects selected before } \\
\text { disease detection; 3-Can } \\
\text { study several outcomes for } \\
\text { each exposure. }\end{array}$ & $\begin{array}{l}\text { 1- Expensive and } \\
\text { time-consuming; 2- } \\
\text { Inefficient for rare diseases or } \\
\text { diseases with long latency; 3- } \\
\text { Loss to follow-up. }\end{array}$ \\
\hline & $\begin{array}{l}\text { Randomized controlled } \\
\text { trial }\end{array}$ & $\begin{array}{l}\text { Test the relationship } \\
\text { experimentally }\end{array}$ & $\begin{array}{l}\text { 1- Investigator can "control" } \\
\text { the exposure; } 2 \text { - Subjects } \\
\text { randomly assigned to } \\
\text { treatment" and "comparison" } \\
\text { groups; 3- Akin to laboratory } \\
\text { experiments except living } \\
\text { subjects. }\end{array}$ & $\begin{array}{l}\text { 1-Very expensive; } 2 \text { - Not } \\
\text { appropriate to answer certain } \\
\text { types of questions (Unethical } \\
\text { in some cases e.g. assigning } \\
\text { persons to certain treatment } \\
\text { or comparison groups). }\end{array}$ \\
\hline
\end{tabular}

which results in low sample size. In a situation in which RCTs are not possible, an alternative approach is practical to utilize the observational studies with regards its limiting power. However, it is essential to consider that descriptive studies have a critical role in hypotheses generation, whereas analytical studies are able to investigate the association between exposure and outcome.

\section{References}

1. Machin D, Fayers PM. Randomized clinical trials: design, practice and reporting. John Wiley \& Sons; 2010. doi: 10.1002/9780470686232.

2. Mingrone G, Panunzi S, De Gaetano A, Guidone C, Iaconelli A, Nanni $\mathrm{G}$, et al. Bariatric-metabolic surgery versus conventional medical treatment in obese patients with type 2 diabetes: 5 year follow-up of an open-label, single-centre, randomised controlled trial. Lancet. 2015;386(9997):964-73. doi: 10.1016/S0140-6736(15)00075-6. [PubMed: 26369473].

3. Martins Tde C, Duarte TC, Mosca ER, Pinheiro Cde F, Marcola MA, De-Souza DA. Severe protein malnutrition in a morbidly obese patient after bariatric surgery. Nutrition. 2015;31(3):535-8. doi: 10.1016/j.nut.2014.10.011. [PubMed: 25701346].

4. Dekkers OM, Egger M, Altman DG, Vandenbroucke JP. Distinguishing case series from cohort studies. Ann Intern Med. 2012;156(1 Pt 1):37-40. doi: 10.7326/0003-4819-156-1-201201030-00006. [PubMed: 22213493].

5. Rosenbaum PR. Observational Studies. Springer; 2002. doi: 10.1007/978-1-4757-3692-2_1.
6. Van Looveren R, Mandeville Y, Logghe P, Vandendriessche K, Verbeke $\mathrm{X}$, Vuylsteke $\mathrm{P}$, et al. The Effect of Dumping on Weight Loss in Conversion of Failed Restrictive Surgery: a Cross-Sectional Pilot Study. Obes Surg. 2018;28(3):665-70. doi: 10.1007/s11695-017-2906-0. [PubMed: 28933032].

7. Grimes DA, Schulz KF. Cohort studies: marching towards outcomes. Lancet. 2002;359(9303):341-5. doi: 10.1016/S0140-6736(02)07500-1. [PubMed: 11830217].

8. Petersen I, Douglas I, Whitaker H. Self controlled case series methods: an alternative to standard epidemiological study designs. BMJ. 2016;354. i4515. doi: 10.1136/bmj.i4515. [PubMed: 27618829].

9. Tsamalaidze L, Stauffer JA, Arasi LC, Villacreses DE, Franco JSS, Bowers S, et al. Laparoscopic Sleeve Gastrectomy for Morbid Obesity in Patients After Orthotopic Liver Transplant: a Matched Case-Control Study. Obes Surg. 2018;28(2):444-50. doi: 10.1007/s11695-017-2847-7. [PubMed: 28766265].

10. Schulz KF, Grimes DA. Case-control studies: research in reverse. Lancet. 2002;359(9304):431-4. doi: 10.1016/S0140-6736(02)07605-5. [PubMed: 11844534].

11. Castelli WP. Epidemiology of coronary heart disease: the Framingham study. Am J Med. 1984;76(2A):4-12. doi: 10.1016/00029343(84)90952-5. [PubMed: 6702862].

12. Luyssen J, Jans G, Bogaerts A, Ceulemans D, Matthys C, Van der Schueren B, et al. Contraception, Menstruation, and Sexuality after Bariatric Surgery: a Prospective Cohort Study. Obes Surg. 2017. doi: 10.1007/s11695-017-3033-7. [PubMed: 29197048].

13. Hedenbro JL, Naslund E, Boman L, Lundegardh G, Bylund A, Ekelund $\mathrm{M}$, et al. Formation of the Scandinavian Obesity Surgery Registry, 
SOReg. Obes Surg. 2015;25(10):1893-900. doi: 10.1007/s11695-015-1619-5 [PubMed: 25703826].

14. Torgerson JS, Sjostrom L. The Swedish Obese Subjects (SOS) studyrationale and results. Int J Obes Relat Metab Disord. 2001;25 Suppl 1:S2-
4. doi: 10.1038/sj.ijo.0801687. [PubMed: 11466577].

15. Minimally Invasive Surgery Research \&amp; Training Center of Excellence . Obesity Surgery. 2015. Available from: http://obesitysurgery.ir/. 